\title{
Self-assembly and antimicrobial activity of long-chain amide- functionalized ionic liquids in aqueous solution
}

M. Teresa Garcia, ${ }^{\mathrm{a},}{ }^{*}$ Isabel Ribosa, ${ }^{\mathrm{a}}$ Lourdes Perez, ${ }^{\mathrm{a}}$ Angeles Manresa, ${ }^{\mathrm{b}}$ Francesc Comelles ${ }^{\mathrm{a}}$

${ }^{a}$ Department of Chemical and Surfactant Technology, Institut of Advanced Chemistry of Catalonia IQAC- CSIC, Jordi Girona 18-26, 08034 Barcelona, Spain

${ }^{\mathrm{b}}$ Facultat de Farmacia, Universitat de Barcelona, Joan XXIII, 08028 Barcelona, Spain

* Corresponding author. E-mail address: teresa.garcia@iqac.csic.es (M.T. Garcia)

Tel.: +34 34006100; Fax: +34 32045904 


\section{ABSTRACT}

Surface active amide-functionalized ionic liquids (ILs) consisting of a long alkyl chain $\left(\mathrm{C}_{6}-\mathrm{C}_{14}\right)$ connected to a polar head group (methylimidazolium or pyridinium cation) via an amide functional group were synthesized and their thermal stability, micellar properties and antimicrobial activity in aqueous solution investigated. The incorporation of an amide group increased the thermal stability of the functionalized ionic liquids compared to simple alkyl chain substituted ionic liquids. The surface activity and aggregation behaviour in aqueous solution of amide-functionalized ionic liquids were examined by tensiometry, conductivity and spectrofluorimetry. Amide-functionalized ILs displayed surface activity and their critical micelle concentration $(\mathrm{cmc})$ in aqueous media decreased with the elongation of the alkyl side chain as occurs for typical surfactants. Compared to non-functionalized ILs bearing the same alkyl chain, ionic liquids with an amide moiety possess higher surface activity $\left(\mathrm{pC}_{20}\right)$ and lower cmc values. The introduction of an amide group in the hydrophobic chain close to the polar head enhances adsorption at the air/water interface and micellization which could be attributed to the H-bonding in the headgroup region. The antimicrobial activity was evaluated against a panel of representative Gram-negative and Gram-positive bacteria and fungi. Amide-functionalized ILs with more than eight carbon atoms in the side chain showed broad antimicrobial activity. Antibacterial activities were found to increase with the alkyl chain length being the $C_{12}$ homologous the most effective antimicrobial agents. The introduction of an amide group enhanced significantly the antifungal activity as compared to non-functionalized ILs.

\section{Keywords}

Functionalized ionic liquids, surface activity, aggregation behavior, antimicrobial activity 


\section{Introduction}

Ionic liquids are currently receiving increasing interest as a new class of non-molecular, ionic solvents in organic synthesis, catalysis, separation processes and preparation of nanostructured materials [1-6]. Most widely studied ILs are comprised of bulky, asymmetric N-containing organic cations in combination with any wide variety of anions, ranging from simple inorganic anions to more complex organic species [1]. Due to their negligible vapour pressure and nonflammability they are regarded as environmentally friendly alternatives to volatile organic solvents. In addition, their properties such as hydrophilicity/hydrophobicity and miscibility with organic solvents or water can be tuned by changing the $\mathrm{N}$-alkyl substituents and/or the anion $[7,8]$. Moreover, the incorporation of functional groups as a part of the cation and/or anion can impart a particular capability to the ionic liquid for specific purposes [9]. For example, longchain ether-functionalized ionic liquids have been reported as novel media for specific homogenous enzymatic reactions [10] and a hydrophobic amide-functionalized ionic liquid has been used for selective extraction of tryptophan with higher extraction efficiency [11].

Imidazolium and pyridinium ionic liquids with alkyl side chains longer than four are generally regarded as amphiphilic compounds and behave as typical cationic surfactants in aqueous solution[12-16]. The self-organization of ionic liquids in aqueous solution may have significant effects on a variety of processes such as the extraction of compounds from IL-containing systems, the synthesis and purification of bulk ILs, the formation of dispersed or phase separated systems, etc. [17]. On the other hand, it can be expected that the incorporation of a specific functional group in the alkyl side chain attached to the cation affects the surface properties of amphiphilic ILs. Recent studies have reported that $\mathrm{COOH}$-functionalized imidazolium ILs [18], 
long-chain $\beta$-hydroxy- $\gamma$-alkyloxy-N-methylimidazolium ILs [19] and amphiphilic imidazolium and pyridinium ILs with an ester group in the alkyl tail [20] show superior surface activity compared with simple alkyl chain substituted derivatives [16].

Long-chain imidazolium- and pyridinium-based ionic liquids can exhibit, besides to interfacial activity, significant biological activity against bacteria and fungi $[16,17,21]$. Cornellas et al.[16] found that antimicrobial activity of amphiphilic imidazolium and pyridinium ILs is closely related to their surfactant properties. Likewise, toxicology data indicate a strong correlation between the length of the alkyl chain attached to the IL cation and the resulting toxicity $[22,23]$. On the other hand, some authors have analyzed the effect of incorporating a specific functional group in the IL structure on its biological activity. Morrisey et al. [24] reported a notable diminution of the antimicrobial activity for imidazolium ILs containing ether or polyether side chains compared with the alkyl substituted derivatives whereas Garcia et al. [20] observed a significant increase in antifungal activity for ILs by introducing an ester moiety.

The ability of some organic functionalities to modify the specific properties of the ionic liquids by their incorporation in the cation and/or anion structure prompted us to synthesize a series of long-chain amide-functionalized ionic liquids in order to investigate the effect of a strong hydrogen bonding functionality, the amide group, on the physico-chemical and biological properties of amphiphilic ILs. In the present work, two series of ionic liquids based on imidazolium and pyridinium cations containing an amide functional group in the hydrophobic side chain attached to the polar head, 1-alkylcarbamylmethyl-3-methylimidazolium bromides and 1-alkylcarbamylmethylpyridinium bromides, have been synthesized and the effect of incorporating a strong hydrogen bonding functionality on their thermal stability, aggregation behavior and antimicrobial activity investigated. The research is expected to contribute to further 
development of new functionalized ILs with higher surface and biological activities and improved thermal stability for specific purposes such as separation processes, biocatalysis and preparation of nanoestructured materials.

\section{Experimental}

\subsection{Synthesis of long-chain amide-functionalized ionic liquids}

1-alkylcarbamylmethyl-3-methylimidazolium bromides $\quad\left[\mathrm{C}_{\mathrm{n}} \mathrm{AMeImBr}\right] \quad$ and 1 alkylcarbamylmethylpyridinium bromides $\left[\mathrm{C}_{n} \mathrm{APyrBr}\right]$ were synthesized in two steps using standard methodology [24-26]. First step involved the reaction of the commercially available amines with bromoacetyl bromide to form the desired alkylating agents. Subsequent alkylation of either methylimidazole or pyridine led to the imidazolium- or pyridinium-based ionic liquids, respectively. Experimental details of the synthesis and analytical data and spectra of the ILs synthesized are reported in the Supplementary data (Appendix A). The molecular structures of the amide functionalized ILs synthesized are given in Fig. 1.

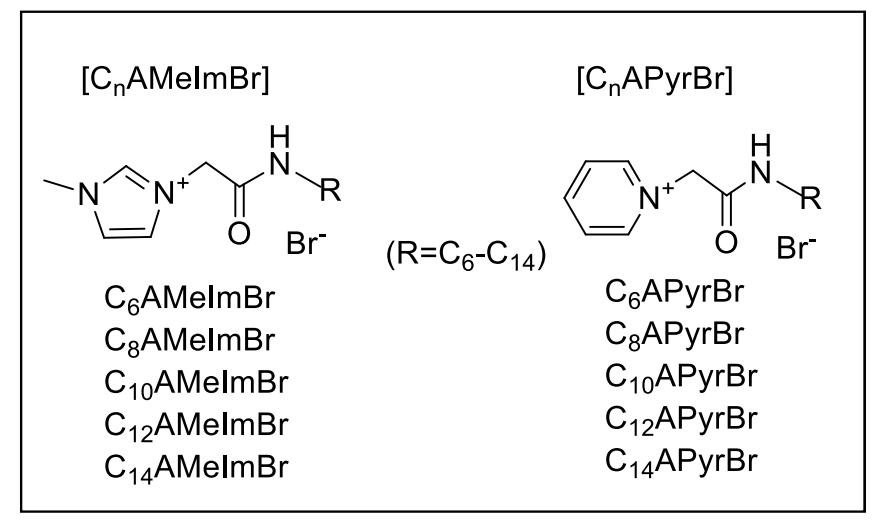

Fig. 1. Structure of the amide-functionalized ionic liquids 


\subsection{Thermal stability measurements}

Thermal stability of the amide-functionalized ILs was measured with a Mettler Toledo TGA/STGA 851 thermal gravimetric analyzer using a nitrogen atmosphere. All samples were run in aluminium pans by using a nitrogen flow rate of $20 \mathrm{~mL} / \mathrm{min}$. Thermograms were recorded using a heating rate of $10{ }^{\circ} \mathrm{C} / \mathrm{min}$ from 25 to $550^{\circ} \mathrm{C}$.

\subsection{Conductivity measurements}

Conductivity was measured at $25^{\circ} \mathrm{C}$ using an Orion Conductivity Cell 913005MD with epoxy/graphite electrode in conjunction with a Thermo Orion 5 Star multiparameter instrument with a cell constant of $0.475 \mathrm{~cm}^{-1}$.

\subsection{Surface tension measurements}

Surface tension was measured at $25^{\circ} \mathrm{C}$ by the Wilhelmy plate technique using a Krüss K-12 tensiometer. Glass containers and plate were cleaned with chromic acid solution and rinsed thoroughly with distilled water. The plate was flame dried before each measurement. Surface tension was considered to be at equilibrium when the standard deviation of five consecutive measurements did not exceed $0.10 \mathrm{mN} / \mathrm{m}$.

\subsection{Fluorescence measurements}

Steady-state fluorescence measurements were performed with a Shidmadzu RF 540 spectrofluorometer equipped with a thermostated cell holder at $25^{\circ} \mathrm{C}$. Both excitation and emission band slits were fixed at $2 \mathrm{~nm}$. All data were acquired using quartz cells with a $1 \mathrm{~cm}$ path length. Pyrene was used as fluorescence probe and its concentration was kept at $1 \times 10^{-6} \mathrm{M}$.

\subsubsection{Steady state fluorescence measurements for $C_{n} A M e I m B r$}

The emission spectra of micelle-solubilized pyrene were employed for the determination of the cmc values of the amide-functionalized imidazolium-based ILs. Pyrene exhibits a fine structure 
in the $370-400 \mathrm{~nm}$ region of the steady-state fluorescence emission spectra. The nature and the intensity are extremely dependent on the polarity of the environment. The ratio of the first to the third vibronic peaks, $I_{1} / I_{3}\left(I_{1}\right.$ at $374 \mathrm{~nm}$ and $I_{3}$ at $\left.384 \mathrm{~nm}\right)$, shows the greatest solvent dependency and hence can be used to probe the micropolarity of the aggregates and obtain the $\mathrm{cmc}$ of the long-chain imidazolium-based ILs in aqueous solution [27,28].

\subsubsection{Steady state fluorescence measurements for $C_{n} A P y r B r$}

Fluorescence probe, pyrene, was used in order to ascertain the onset of the aggregation of pyridinium-based ionic liquids in water $[15,20]$.The excitation wavelength used for pyrenecontaining samples was $332 \mathrm{~nm}$. The fluorescence was collected at $374 \mathrm{~nm}$, the wavelength of the first vibronic emission band, and the ratio $\mathrm{I}_{0} / \mathrm{I}$ (fluorescence intensity of pyrene in absence, $\mathrm{I}_{\mathrm{o}}$, and presence, I, of ionic liquid) was determined.

\subsection{Antimicrobial Activity}

Antimicrobial tests were carried out using bacteria and fungi which are stored in our laboratory. Microorganisms were Kocuria rhizophila ATCC9341, Staphylococcus epidermis ATCC12228, Staphylococcus aureus ATCC5638, Escherichia coli ATCC27325, Klebsiella pneumonia ATCC13882, Pseudomonas aeruginosa ATCC9027, Candida albicans ATCC10231 and Bacillus subtilis ATCC6633. The antimicrobial activities were determined in vitro on the basis of the minimum inhibitory concentration (MIC) values [29] defined as the lowest concentration of antimicrobial agent that inhibits the development of visible growth after $24 \mathrm{~h}$ of incubation at $37^{\circ} \mathrm{C}$. The ionic liquids tested were dissolved in Mueller-Hinton broth (MBH) in the concentration range of $0.1-256 \mu \mathrm{g} / \mathrm{mL}$ and no precipitate was observed at the highest concentration of the ILs. The MHB was prepared according to the manufacturer instructions. Then $10 \mu \mathrm{L}$ of a nutrient broth starter culture of each bacterial strain was added to achieve final 
inoculums of ca. $5 \times 10^{-4}-5 \times 10^{-5}$ colony forming units per mL. Nutrient broth medium without the compound served as control. The growth of the microorganisms was determined visually after incubation for 24 hour at $37^{\circ} \mathrm{C}$. The development of turbidity in an inoculated medium is a function of growth. A rise in turbidity reflects increases in both mass and cell number. Changes in turbidity were correlated with changes in cell numbers. All the experiments were performed in triplicate. The lowest concentration of antimicrobial agent at which no visible turbidity was observed was taken as the minimum inhibitory concentration.

\section{Results and discussion}

\subsection{Thermal stability}

Thermal stability of the amide-functionalized ILs has been determined by TGA analysis. The characteristic thermal weight loss curves for amide-containing imidazolium and pyridinium ILs in nitrogen atmosphere are given in the Supplementary data (Appendix A). The decomposition onset temperature is determined from the intersection of the baseline weight and the tangent of the weight versus temperature curve as decomposition occurs [30].

The decomposition temperatures of the amide-functionalized ILs herein investigated are displayed in Table 1. For the sake of comparison, the decomposition temperatures of nonfunctionalized ILs (1-alkyl-3-methylimidazolium and 1-alkylpyridinium bromides, $\left[\mathrm{C}_{\mathrm{n}} \mathrm{MeImBr}\right]$ and $\left[\mathrm{C}_{\mathrm{n}} \mathrm{PyrBr}\right]$, respectively) and ester-functionalized ILs (1-alkyloxycarbonylmethyl-3methylimidazolium and 1-alkyloxycarbonylmethylpyridinium bromides, $\left[\mathrm{C}_{\mathrm{n}} \mathrm{EMeImB}\right]$ and $\left[\mathrm{C}_{\mathrm{n}} \mathrm{EPyrBr}\right]$, respectively) are also displayed in Table 1. 


\section{Table 1}

Thermal decomposition temperatures $\left(\mathrm{T}_{\text {onset }}\right)$ of amide-functionalized ILs $\left(\mathrm{C}_{\mathrm{n}} \mathrm{AMeImBr}\right.$ and $\left.\mathrm{C}_{\mathrm{n}} \mathrm{APyrBr}\right)$, non-functionalized ILs $\left(\mathrm{C}_{\mathrm{n}} \mathrm{MeImBr}\right.$ and $\left.\mathrm{C}_{\mathrm{n}} \mathrm{PyrBr}\right)$ and ester-functionalized ILs $\left(\mathrm{C}_{\mathrm{n}} \mathrm{EMeImBr}\right.$ and $\left.\mathrm{C}_{\mathrm{n}} \mathrm{EPyrBr}\right)$

\begin{tabular}{|c|c|c|}
\hline & Ionic liquid & $\mathrm{T}_{\text {onset }} /{ }^{\circ} \mathrm{C}$ \\
\hline \multirow{5}{*}{$\begin{array}{l}\text { Amide-functionalized } \\
\text { imidazolium ILs }\end{array}$} & $\mathrm{C}_{6} \mathrm{AMeImBr}$ & 310 \\
\hline & $\mathrm{C}_{8} \mathrm{AMeImBr}$ & 314 \\
\hline & $\mathrm{C}_{10} \mathrm{AMeImBr}$ & 319 \\
\hline & $\mathrm{C}_{12} \mathrm{AMeImBr}$ & 318 \\
\hline & $\mathrm{C}_{14} \mathrm{AMeImBr}$ & 321 \\
\hline \multirow{5}{*}{$\begin{array}{l}\text { Amide-functionalized } \\
\text { pyridinium ILs }\end{array}$} & $\mathrm{C}_{6} \mathrm{APyrBr}$ & 260 \\
\hline & $\mathrm{C}_{8} \mathrm{APyrBr}$ & 256 \\
\hline & $\mathrm{C}_{10} \mathrm{APyrBr}$ & 260 \\
\hline & $\mathrm{C}_{12} \mathrm{APyrBr}$ & 258 \\
\hline & $\mathrm{C}_{14} \mathrm{APyrBr}$ & 259 \\
\hline \multirow{3}{*}{$\begin{array}{l}\text { Non-functionalized } \\
\text { imidazolium ILs }\end{array}$} & $\mathrm{C}_{4} \mathrm{MeImBr}$ & $278[31]$ \\
\hline & $\mathrm{C}_{8} \mathrm{MeImBr}$ & $282[31]$ \\
\hline & C10MeImBr & 288 [20] \\
\hline $\begin{array}{l}\text { Non-functionalized } \\
\text { pyridinium ILs }\end{array}$ & C12PyrBr & $232[20]$ \\
\hline $\begin{array}{l}\text { Ester-functionalized } \\
\text { imidazolium ILs }\end{array}$ & $\mathrm{C}_{6}-\mathrm{C}_{14} \mathrm{EMeImBr}$ & $210-228[20]$ \\
\hline $\begin{array}{l}\text { Ester-functionalized } \\
\text { pyridinium ILs }\end{array}$ & $\mathrm{C}_{6}-\mathrm{C}_{14} \mathrm{EPyrBr}$ & $158-162[20]$ \\
\hline
\end{tabular}

As shown in Table 1, amide-functionalized imidazolium ILs exhibit substantially higher thermal stabilities than amide-functionalized pyridinium compounds since the onset of thermal degradation of the imidazolium salts occurs at $310-321^{\circ} \mathrm{C}$ whereas for the pyridinium salts it 
occurs at $258-260^{\circ} \mathrm{C}$. The alkyl chain length does not significantly affect the thermal stability of the functionalized- pyridinium ILs but increasing the cation size produces a slight increase in the decomposition onset temperature of the imidazolium compounds. These results are in good agreement with those reported by Arellano [31] and Huddleston [32] about the effect of increasing the cation size on thermal stability of 1-alkyl-3 methyl imidazolium salts and with those reported by Garcia et al. [20] for the ester-functionalized imidazolium and pyridinium bromides.

Compared to non-functionalized ILs, the incorporation of an amide group in the alkyl side chain results in an increase of $20-40{ }^{\circ} \mathrm{C}$ in the decomposition onset temperature for the imidazolium ILs and $24-28^{\circ} \mathrm{C}$ for the pyridinium-based ILs (Table 1). The higher thermal stability observed for amide-functionalized ILs can be attributed to the intermolecular hydrogen bonding imparted by the amide group which impacts the organization of molecules in the sample [31]. On the other hand, thermal degradation of imidazolium- and pyridinium-based ILs containing an ester group occurs at temperatures about $100^{\circ} \mathrm{C}$ lower than their corresponding amide-functionalized analogues (Table 1). The introduction of an ester group decreases dramatically the decomposition onset temperature of the ionic liquid whereas the incorporation of an amide functionality increases its thermal stability. Therefore, the upper range of operating temperatures is greater for amide-functionalized ILs than for the corresponding ester derivatives.

\subsection{Aggregation behaviour in aqueous solution}

The aggregation properties of the amide-functionalized ionic liquids in aqueous solution have been studied by means of conductivity, surface tension, and fluorescence measurements. The 
data obtained are summarized in Table 2. In the following subsections the details and discussion of the results obtained by each of the techniques are given.

\section{Table 2}

Aggregation parameters of 1-alkylcarbamylmethyl-3-methylimidazolium bromides $\left[\mathrm{C}_{\mathrm{n}} \mathrm{AMeImBr}\right]$ and 1-alkylcarbamylmethylpyridinium bromides $\left[\mathrm{C}_{\mathrm{n}} \mathrm{APyrBr}\right]$ in aqueous solution at $25^{\circ} \mathrm{C}$ obtained by conductivity, surface tension and fluorescence

\begin{tabular}{|c|c|c|c|c|c|c|c|}
\hline \multirow[t]{2}{*}{ ILs } & \multicolumn{3}{|c|}{ conductivity } & \multicolumn{3}{|c|}{ surface tension } & \multirow{2}{*}{$\begin{array}{l}\text { fluorescence } \\
\mathrm{cmc} \\
(\mathrm{mM})\end{array}$} \\
\hline & $\begin{array}{l}\mathrm{cmc} \\
(\mathrm{mM})\end{array}$ & $\beta$ & $\begin{array}{l}\Delta \mathrm{G}_{\text {mic }}^{\mathrm{O}} \\
(\mathrm{kJ} / \mathrm{mol})\end{array}$ & $\begin{array}{l}\mathrm{cmc} \\
(\mathrm{mM})\end{array}$ & $\begin{array}{l}\pi_{\mathrm{cmc}} \\
(\mathrm{mN} / \mathrm{m})\end{array}$ & $\mathrm{pC}_{20}$ & \\
\hline $\mathrm{C}_{6} \mathrm{AMeImBr}$ & 278 & 0.31 & -17.2 & - & - & - & - \\
\hline $\mathrm{C}_{8} \mathrm{AMeImBr}$ & 77 & 0.53 & -25.0 & 65 & 44 & 1.9 & 80 \\
\hline $\mathrm{C}_{10} \mathrm{AMeImBr}$ & 19 & 0.65 & -32.6 & 16 & 43 & 2.3 & 15 \\
\hline $\mathrm{C}_{12} \mathrm{AMeImBr}$ & 5.2 & 0.62 & -37.3 & 5.5 & 37 & 3.0 & 6.0 \\
\hline $\mathrm{C}_{14} \mathrm{AMeImBr}$ & 1.2 & 0.71 & -45.6 & 0.95 & 35 & 3.7 & 1.2 \\
\hline $\mathrm{C}_{6} \mathrm{APyrBr}$ & 262 & 0.41 & -18.7 & - & - & - & - \\
\hline $\mathrm{C}_{8} \mathrm{APyrBr}$ & 73 & 0.60 & -26.2 & 70 & 42 & 1.8 & - \\
\hline $\mathrm{C}_{10} \mathrm{APyrBr}$ & 18 & 0.71 & -34.0 & 12 & 45 & 2.8 & 18 \\
\hline $\mathrm{C}_{12} \mathrm{APyrBr}$ & 4.6 & 0.70 & -39.6 & 4.8 & 37 & 3.6 & 3.4 \\
\hline $\mathrm{C}_{14} \mathrm{APyrBr}$ & 1.2 & 0.67 & -44.5 & 1.0 & 36 & 4.1 & 1.1 \\
\hline
\end{tabular}

critical micelle concentration (cmc), degree of counterion association $(\beta)$, Gibbs free energy of micellization $\left(\Delta \mathrm{G}^{\mathrm{o}}{ }_{\mathrm{mic}}\right)$, adsorption effectiveness $\left(\pi_{\mathrm{cmc}}\right)$ and adsorption efficiency $\left(\mathrm{pC}_{20}\right)$ of the amide-functionalized imidazolium- and pyridinium-based ILs. The coefficients of variation of cmc values determined by conductivity, surface tension and fluorescence were calculated from three independent determinations of $\mathrm{cmc}$ and were found to be $\leq 5 \%, \leq 12 \%$ and $\leq 7 \%$, respectively. 


\subsubsection{Conductivity measurements}

The critical micelle concentration $(\mathrm{cmc}$ ) was determined by measuring the change in specific conductivity ( $\kappa$ ) for aqueous solutions of $\mathrm{CnAMeImBr}$ and $\mathrm{CnAPyrBr}$ as a function of the ionic liquid concentration. Representative results are displayed in Fig. 2 for two of the homologues investigated. The plots for the rest of the amide-functionalized ILs studied are given in the Supplementary data (Appendix A).
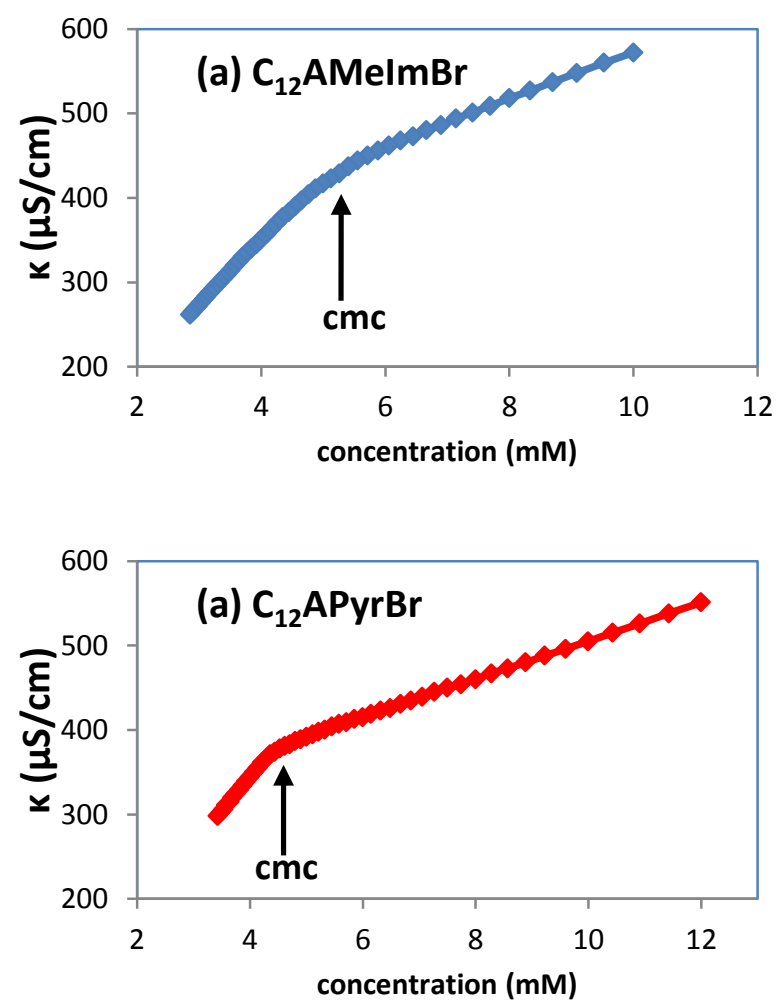

Fig. 2. Specific conductivity versus ionic liquid concentration in water at $25^{\circ} \mathrm{C}$ for $\mathrm{C}_{12} \mathrm{AMeImBr}$ (a) and $\mathrm{C}_{12} \mathrm{APyrBr}(\mathrm{b})$

The specific conductivity values fit into two straight lines of different slopes and from the location of the change of slopes the corresponding value was derived for the cmc. The conductivity below the $\mathrm{cmc}$ is due to the sum of the contributions of the free ions. Above the 
cmc the rate augmentation of the specific conductivity is lower because the micelles can contribute to the charge transport to a lesser extent than the free ions owing to their lower mobility and to the effective loss of ionic charge as a result of the binding of a fraction of counterions to the micellar surface $[20,33,34]$. The counterion binding parameter $(\beta)$ gives the extent of counter ion association and can be estimated from the ratio of the slopes above and below the cmc [35]. The cmc and $\beta$ values obtained by a least-squares analysis are presented in Table 2 .

For both series of amide-functionalized ionic liquids $\left(\mathrm{C}_{\mathrm{n}} \mathrm{AMeImBr}\right.$ and $\left.\mathrm{C}_{\mathrm{n}} \mathrm{APyrBr}\right)$ the $\mathrm{cmc}$ decreases with increasing the alkyl chain length (Table 2). This behaviour is analogous to that reported for different functionalized $[19,20,26,33]$ and non-functionalized amphiphilic ILs $[14,16,36,37]$, as well as for ionic surfactants [38-40].

The correlation between the $\mathrm{cmc}$ and the number of carbon atoms in the hydrocarbon chain for amide-functionalized ILs is shown in Fig. 3. The $\log \mathrm{cmc}$ value decreases linearly with the increase in n, following the empirical Klevens equation [41]:

$$
\log c m c=A-B n
$$

where $\mathrm{A}$ and $\mathrm{B}$ are constants for a particular homologous series at a constant temperature. The parameter $\mathrm{A}$ is related to the contribution of the polar head to micelle formation, and the parameter $\mathrm{B}$ indicates the average contribution to the micelle formation of each additional methylene group in the hydrophobic chain. 


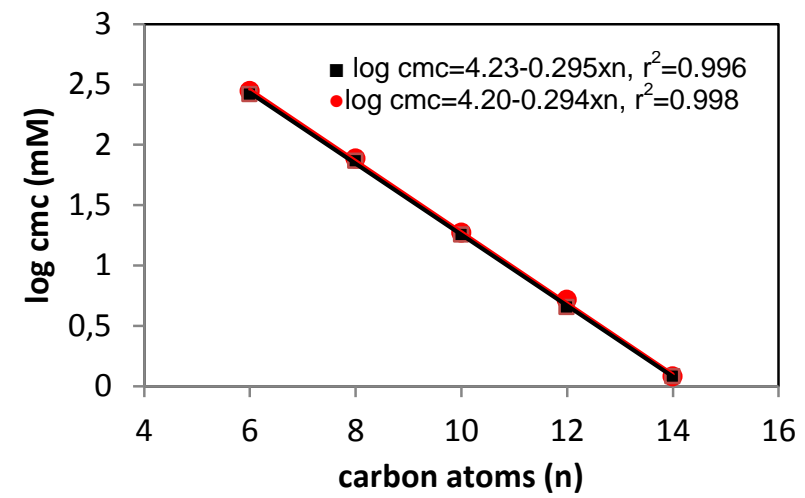

Fig. 3. Effect of the alkyl chain length on the cmc for $\mathrm{C}_{\mathrm{n}} \mathrm{AMeImBr}(\boldsymbol{\square})$ and $\mathrm{C}_{\mathrm{n}} \mathrm{APyrBr}(\bullet)$ in aqueous solution at $25^{\circ} \mathrm{C}$

Amide-functionalized ILs show the characteristic slope values (0.28-0.30) reported for conventional ionic surfactants [39] and long-chain non-functionalized imidazolium [16,36,42] and pyridinium-based ILs [16]. It means that one more $\mathrm{CH}_{2}$ group in the alkyl tail approximately halves the cmc values of the corresponding ionic liquid.

Comparing imidazolium to pyridinium type ionic liquids bearing alkyl chains of the same length we find very similar cmc values (Table 2) which indicates that both heterocyclic head groups possess similar hydrophilicity and ease of packing their planar structures into the micelle. Amide-functionalized ILs exhibit a 2-3 fold decrease in cmc values (Table 2) as compared to the corresponding non-functionalized homologous [16]. The introduction of the amide functional group leads to a reduction in the cmc value that could be attributed to the increased $\mathrm{H}$-bonding in the head group region $[26,40,43]$.

Compared to other functionalized ILs, the tendency to form micellar aggregates of the amidefunctionalized ILs (Table 2) is very similar to that of ILs containing an ester functional group [20]. The cmc values of amide-functionalized imidazolium ILs are also similar to those reported for $\beta$-hydroxy- $\gamma$-alkoxy-N-mehtylimidazolium ILs [19]. On the other hand, the cmc values of 
amide functionalized ILs are approximately double than those reported for long-chain $\mathrm{N}$-aryl imidazolium ILs [44] and also higher than those described for ILs functionalized with a carboxylic group [18].

The values of the counterion binding parameter $\beta$ (Table 2 ) increased with the length of the alkyl side chain similarly as reported for non-functionalized ILs [14,16,27,43]. Thus, the counterion is stronger bonded to the aggregate as the alkyl chain becomes longer. Applying the phase separation model to the monomer-micelle equilibrium for cationic amphiphile, the standard Gibbs energy of micellization $\left(\Delta \mathrm{G}^{0}\right.$ mic $)$ can be calculated from the following equation [45]:

$$
\Delta G_{m i c}^{o}=(1+\beta) \mathrm{RT} \ln x_{c m c}
$$

Where $\beta$ is the fraction of counterions condensed in the micellar interface and $x_{\mathrm{cmc}}$ is the critical micellar concentration expressed as mole fraction. $\Delta \mathrm{G}^{\mathrm{o}}$ mic indicates the free energy difference per mol between molecules in water and in micelles and also the free energy of transfer $1 \mathrm{~mol}$ of IL from the aqueous phase to the micellar pseudophase. The values of $\Delta \mathrm{G}^{\mathrm{o}}$ mic calculated for the ILs are given in Table 2. These values are negative and give evidence that the micelle formation in aqueous solution of the amide-functionalized ionic liquids investigated is a spontaneous process. The longer the alkyl chain, the lower the free energy of Gibbs. This iindicates that the aggregation process becomes more favourable as the alkyl chain length increases.

\subsubsection{Surface tension measurements}

Surface tension data were measured in order to establish the surface activity and the aggregation concentration in aqueous solution of the ILs containing an amide functional group. 
The plot of surface tension $(\gamma)$ versus the logarithm of the ionic liquid concentration for the $\mathrm{C}_{\mathrm{n}} \mathrm{AMeImBr}$ and $\mathrm{C}_{\mathrm{n}} \mathrm{APyrBr}$ series is shown in Fig. 4.
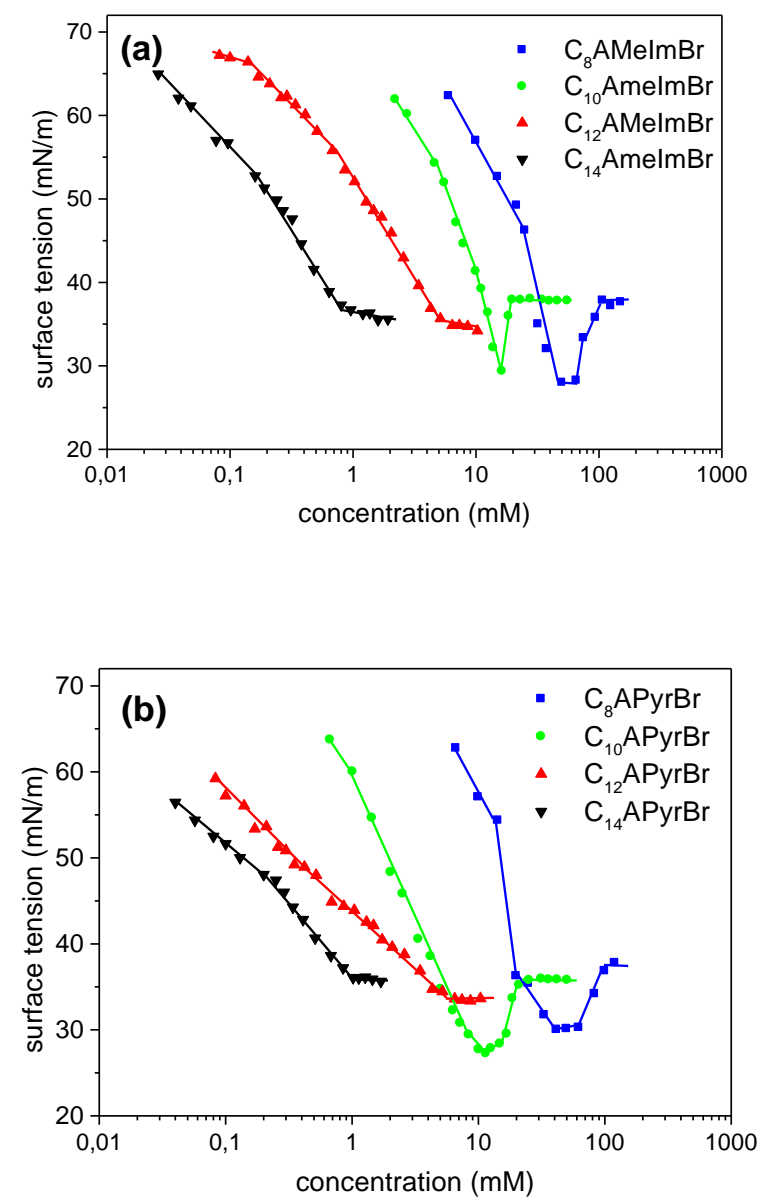

Fig. 4. Surface tension as a function of concentration for amide-functionalized imidazolium ILs (a) and amide-functionalized pyridinium ILs (b) in water at $25^{\circ} \mathrm{C}$

The lowering of the surface tension values with increasing the ionic liquid concentration from the water value to a plateau region is a consequence of the increased concentration of the $\mathrm{C}_{\mathrm{n}} \mathrm{AMeImBr}$ and $\mathrm{C}_{\mathrm{n}} \mathrm{APyrBr}$ compounds at the air-water surface. For the shorter chain homologues of the $C_{n} A M e I m B r$ and $C_{n} A P y r B r$ series $\left(C_{8}\right.$ and $\left.C_{10}\right)$ a minimum of surface tension appears before attaining a plateau. In the case of conventional ionic surfactants the appearance of 
a minimum in the surface tension isotherm may arise from impurities that adsorb strongly in the liquid/air interface[39] and for these compounds the minimum can be reduced or eliminated by purification. However, the minima displayed in the isotherms for $\mathrm{C}_{8}$ and $\mathrm{C}_{10}$ homologues persisted even after purification of the ILs by repeated crystallization steps. Therefore, it seems reasonably to state that the observed minimum is not due to any impurity in the samples of ILs. The presence of such minima in the surface tension isotherms was already described by other authors for simple alkyl-chain containing ILs, i.e. for 1-alkyl-3-methylimidazolium salts with alkyl chains of 8 or 10 carbon atoms [12,14,46-48] and for 1-alkylpyridinium [16] salts with the same alkyl chain lengths. Goodchild et al. [46] attributed the presence of a minimum in the surface tension isotherm to the formation of surface micelles prior to bulk aggregation which leads to a minimum in the area per molecule and a maximum in adsorbed film thickness and the re-establishment of a surface monolayer at concentrations greater than the $\mathrm{cmc}$. In the present work the cmc was taken as the point at which the surface tension reaches its lowest value. Due to the presence of the above mentioned minimum, the conductivity measurements give a more accurate value of the cmc for the shorter chain homologues. However, it is noteworthy the good agreement between the cmc values obtained by conductivity and by surface tension (Table 2) even for the shorter alkyl chain homologues. For the amide-functionalized ILs, the cmc decreases by increasing the hydrophobicity which makes that the ionic liquids with longer alkyl chains exhibit higher surface activity following the general trend observed for surfactants.

The surface tension isotherms were used to determine two additional adsorption parameters, the efficiency of adsorption, $\mathrm{pC}_{20}$ (defined as the negative logarithm of the concentration of amphiphilic molecules required to reduce the surface tension of the pure solvent by $20 \mathrm{mN} / \mathrm{m}$ ) and the effectiveness of the surface tension reduction, $\Pi_{\mathrm{cmc}}$ (defined as $\Pi_{\mathrm{cmc}}=\gamma_{0}-\gamma_{\mathrm{cmc}}$, where $\gamma_{0}$ is 
surface tension of the pure solvent (water), and $\gamma_{\mathrm{cmc}}$ the surface tension of the solution at the cmc) [39]. The larger the value of $\mathrm{pC}_{20}$ the more efficiently the surfactant is adsorbed at the interface and the more efficiently it reduces surface tension $[13,46]$ The $\mathrm{pC}_{20}$ and $\pi_{\mathrm{cmc}}$ values of the amide-functionalized ILs are displayed in Table 2. The data show that the adsorption efficiency $\left(\mathrm{pC}_{20}\right)$ increases with the elongation of the alkyl chain, being similar for the amideimidazolium and amide-pyridinium homologues at the same alkyl chain length. The effectiveness of the surface tension reduction, $\Pi_{\mathrm{cmc}}$, varies only slightly for the longer alkyl chain homologues $\left(\mathrm{C}_{12}\right.$ and $\left.\mathrm{C}_{14}\right)$. The presence of a minimum in the surface pressure graphs (Fig. 4$)$ for the shorter homologues $\left(\mathrm{C}_{8}\right.$ and $\left.\mathrm{C}_{10}\right)$ results in high $\Pi_{\mathrm{cmc}}$ values. However, the surface tension of the aqueous solutions of the shorter homologues is similar to that observed for the longer homologues at concentrations superior to their cmc values.

Comparing the efficiency of adsorption and the effectiveness of the amide-functionalized ILs (Table 2) to the non-functionalized ILs [16,27] it is clear that the introduction of an amide group improves the surface activity of the IL. Adsorption at the air/water interface is more favourable for amide-functionalized ionic liquids than for non-functionalized ionic liquids because the $\mathrm{CONH}$ - group of the amide-functionalized IL series forms hydrogen bonds to the neighbouring molecules [43].

\subsubsection{Fluorescence measurements}

In order to study the micelle aggregation behavior of the amide-functionalized ILs in aqueous solution steady state fluorescence measurements employing pyrene as the solvatochromic probe were performed, although different experimental protocols were applied to imidazolium and pyridinium salts because of the ability of the pyridinium ionic liquids to act as quenchers of pyrene fluorescence. 
Amide-functionalized imidazolium ionic liquids. The intensity ratio of the first to the third vibronic peaks of pyrene, i.e. $\mathrm{I}_{1} / \mathrm{I}_{3}$, was measured as a function of the ionic liquid concentration (Fig. 5a). The abrupt sigmoidal decrease in $\mathrm{I}_{1} / \mathrm{I}_{3}$ intensity provides evidence of the formation of IL aggregates. The cmc values were taken as the concentration that corresponds to the intersection between the linear extrapolation of the stabilized portion corresponding to low IL concentrations and the abruptly varied portion of the curve.
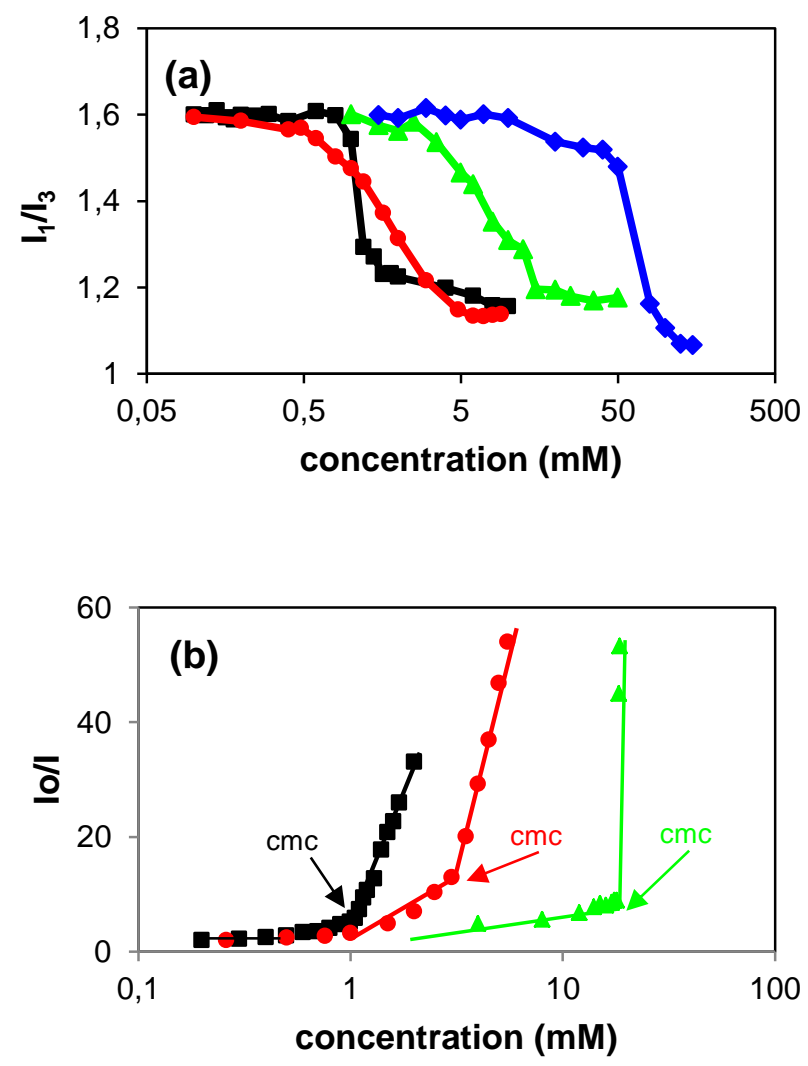

Fig. 5. Monitoring by fluorescence of the self aggregation of amide-functionalized imidazolium ILs (a), $\mathrm{C}_{8} \mathrm{AMeImBr}(\bullet), \mathrm{C}_{10} \mathrm{AMeImBr}(\Delta), \mathrm{C}_{12} \mathrm{AMeImBr}(\bullet)$ and $\mathrm{C}_{14} \mathrm{AMeImBr}(\boldsymbol{\bullet})$, and amide-functionalized pyridinium ILs (b), $\mathrm{C}_{10} \mathrm{APyrBr}(\triangle), \mathrm{C}_{12} \mathrm{APyrBr}(\bullet)$ and $\mathrm{C}_{14} \mathrm{APyr} \mathrm{Br}(\boldsymbol{\bullet})$, in aqueous solution at $25^{\circ} \mathrm{C}$ 
Amide-functionalized pyridinium ionic liquids. The aggregation behavior of the 1alkylcarbamylmethylpyridinium bromides was studied by the method proposed by Blesic et al. [15] to determine the cmc of 1-alkyl-3-methylpyridinium chlorides. The onset of micellization of the pyridinium ionic liquids corresponds to the pronounced break-point in the plot of $\mathrm{I}_{\mathrm{o}} / \mathrm{I}$ (fluorescence intensity of pyrene in the absence, $\mathrm{I}_{0}$, and presence, $\mathrm{I}$, of ionic liquid) versus the concentration of ionic liquid (Fig. 5b). The $\mathrm{cmc}$ of $\mathrm{C}_{6}$ and $\mathrm{C}_{8}$ homologues cannot be determined by this method because the $\mathrm{cmc}$ value of these ILs is higher than the concentration at which complete quenching of pyrene occurs.

Fluorescence measurements provide cmc values for the amide-functionalized ILs investigated that are in good agreement with those obtained by other well-established techniques such as conductivity and surface tension (Table 2).

\subsection{Antimicrobial activity.}

The antimicrobial properties of the amide-functionalized ILs were assessed against seven strains of bacteria (4 Gram-positive and 3 Gram-negative) and one strain of fungi. The antimicrobial activity was determined by measuring minimum inhibitory concentration (MIC) values. The MICs values for amide-functionalized imidazolium and pyridinium ILs are summarized in Table 3. 


\section{Table 3}

MIC values for 1-alkylcarbamylmethyl-3-methylimidazolium bromides $\left[\mathrm{C}_{\mathrm{n}} \mathrm{AMeImBr}\right]$ and for 1-alkylcarbamylmethylpyridinium bromides $\left[\mathrm{C}_{\mathrm{n}} \mathrm{APyrBr}\right]$

\begin{tabular}{|c|c|c|c|c|c|c|c|c|c|c|}
\hline \multirow[b]{3}{*}{ Microorganism } & \multicolumn{10}{|c|}{$\mathrm{MIC}^{*}(\mu \mathrm{M})$} \\
\hline & \multicolumn{5}{|c|}{$\mathrm{C}_{\mathrm{n}} \mathrm{AMelmBr}$} & \multicolumn{5}{|c|}{$\mathrm{C}_{\mathrm{n}} \mathrm{APyrBr}$} \\
\hline & $\mathrm{C}_{6}$ & $\mathrm{C}_{8}$ & $\mathrm{C}_{10}$ & $\mathrm{C}_{12}$ & $\mathrm{C}_{14}$ & $\mathrm{C}_{6}$ & $\mathrm{C}_{8}$ & $\mathrm{C}_{10}$ & $\mathrm{C}_{12}$ & $\mathrm{C}_{14}$ \\
\hline \multicolumn{11}{|l|}{ Gram-positive cocci } \\
\hline K. rhizophila & $\mathrm{R}$ & $\mathrm{R}$ & $\mathrm{R}$ & 21 & 38 & $\mathrm{R}$ & $\mathrm{R}$ & 358 & 83 & 39 \\
\hline S. epidermidis & $\mathrm{R}$ & 770 & 178 & 41 & 77 & $\mathrm{R}$ & 777 & 45 & 10 & 5 \\
\hline S. aureus & $\mathrm{R}$ & $\mathrm{R}$ & 178 & 41 & 77 & $\mathrm{R}$ & $\mathrm{R}$ & 358 & 83 & 39 \\
\hline \multicolumn{11}{|l|}{ Gram-negative rods } \\
\hline E. coli & $\mathrm{R}$ & $\mathrm{R}$ & 710 & 165 & 77 & $\mathrm{R}$ & $\mathrm{R}$ & 716 & 83 & 77 \\
\hline K. pneumoniae & $\mathrm{R}$ & $\mathrm{R}$ & $\mathrm{R}$ & 165 & 154 & $\mathrm{R}$ & $\mathrm{R}$ & $\mathrm{R}$ & 83 & 39 \\
\hline$P$. aeruginosa & $\mathrm{R}$ & $\mathrm{R}$ & $\mathrm{R}$ & $\mathrm{R}$ & $\mathrm{R}$ & $\mathrm{R}$ & $\mathrm{R}$ & 716 & 332 & $\mathrm{R}$ \\
\hline \multicolumn{11}{|l|}{ Fungi } \\
\hline C. albicans & $\mathrm{R}$ & $\mathrm{R}$ & 178 & 165 & 154 & $\mathrm{R}$ & $\mathrm{R}$ & 716 & 83 & 154 \\
\hline \multicolumn{11}{|l|}{ Bacillus } \\
\hline B. subtilis & $\mathrm{R}$ & $\mathrm{R}$ & 355 & 41 & 77 & $\mathrm{R}$ & $\mathrm{R}$ & 716 & 83 & 39 \\
\hline
\end{tabular}

MIC*: the lowest concentration of compound at which the microorganism tested does not show visible growth; R: resistant microorganism at the highest concentration tested $(256 \mathrm{mg} / \mathrm{L})$

The antimicrobial activity of the imidazolium- and pyridinium-based ionic liquids containing an amide functional group (Table 3) depends on the alkyl chain length in keeping with data reported for cationic surfactants[49-51] as well as for simple alkyl chain substituted ionic liquids $[16,21,52]$. The shorter homologous of each series tested $\left(\mathrm{C}_{6}-\mathrm{C}_{8} \mathrm{AMeImBr}\right.$ and $\left.\mathrm{C}_{6}-\mathrm{C}_{8} \mathrm{APyrBr}\right)$ showed low activity (MIC $\geq 256 \mathrm{mg} / \mathrm{L}$ ) against all the microorganisms tested whereas amidecontaining imidazolium and pyridinium salts with more than eight carbon atoms in the alkyl chain showed biological activity against Gram-positive microorganisms. The $\mathrm{C}_{10}, \mathrm{C}_{12}$ and $\mathrm{C}_{14}$ homologous also exhibited activity against most of Gram-negative bacteria, although their 
efficiency was higher against the former. Likewise, $\mathrm{C}_{10}-\mathrm{C}_{14}$ ILs containing an amide functional group showed significant antifungal activity. Gram-positive organisms and fungi were clearly more sensitive to the antimicrobial activity of amide-functionalized ILs than Gram negative rods. On the other hand, the nature of the polar group, imidazolium or pyridinium cation, has not a specific effect on the biological activity of the amide-functionalized ILs (Table 3). This finding corroborates that the hydrophobic character of both polar head groups is similar as also suggested by the study of the ionic liquid surface properties (Table 2).

Compared to simple alkyl chain-containing ILs [16], the incorporation of an amide group in the alkyl chain results in a significant increase of the antimicrobial activity for $\mathrm{C}_{10}-\mathrm{C}_{12}$ homologues whereas $\mathrm{C}_{14}$ homologues show similar biological activity (Table 3). The amide group also enhances significantly the antifungal activity as compared to non-functionalized ILs. [16] This last result is consistent with data reported by Kanjilal et al. [26] for some amidecontaining imidazolium salts. When compared with ILs containing other functional groups, these amide-functionalized ILs posses a similar activity to ILs with an ester moiety in the hydrophobic side chain [20], and they are slightly more effective as antimicrobial agents than 1alkyloxymethyl-3-methylimidazolium salts [21] and much more active than imidazolium derivatives with polyether functional groups in the side chain [24].

Although the biological activity of the amide-functionalized ILs increases with the hydrophobicity of the molecule, for most microorganism strains the MIC values displayed a minimum with increasing alkyl chain length. Thus amide-containing ILs with an alkyl chain of 12 carbon atoms showed the highest efficiency as antimicrobial agents whereas the biological activity remained practically constant or decreased for $\mathrm{C}_{14}$ homologues. The biological effect of an imidazolium or pyridinium salt against a microorganism was attributed to several factors: 
hydrophobicity, adsorption, cmc, solubility and transport in aqueous medium, being the solubility in the test medium the limiting factor for the transport [20,53]. The combination of these factors determined that the amide-functionalized ILs of $\mathrm{C}_{12}$ chain length had the largest tendency to be adsorbed at the bacterial-water interface, and consequently exert their antimicrobial action at the lowest concentration. The optimum efficacy at a certain chain length is consistent with data reported in literature concerning the biological activity of surface active ionic liquids. Thus, maximum efficiency as antimicrobial agents was described for alkylimidazolium and alkyloxyimidazolium lactates containing 11 or 12 carbon atoms in the alkyl chain [21], for alkylimidazolium salts with 12 or 14 carbon atoms in the alkyl chain [16,54], for alkylpyridinium salts with 14 carbon atoms in the alkyl chain[16] and for esterfunctionalized imidazolium and pyridinium bromides with 12 carbon atoms in the side chain.[20]

The mechanism of action of imidazolium and pyridinium salts against common microbes is expected to be similar to that of quaternary ammonium surfactants [55] because of the close resemblance between both type of compounds. The cationic headgroup of the imidazolium- and pyridinium-based ILs will be electrostatically attracted to the bacterial cell wall, while their hydrophobic tails will disturb the cell membrane, leading to leakage of the intracellular substances and ultimately to cell death. Gram-positive bacteria are often more susceptible than gram-negative to treatment with surface active agents because gram-negative bacteria possess an additional outer membrane that prevents adsorption. As reported for QACs [49] and single-alkyl chain-containing ILs [16,21] the antimicrobial activity of amide-functionalized ILs seems to be closely related to their surfactant properties. Amide-derivatives with short alkyl chains $(\leq 8 \mathrm{C})$, and thus weak surfactant properties, were found to be ineffective as antimicrobial agents. The increase of biological activity found for the $\mathrm{C}_{10}-\mathrm{C}_{12}$ amide-functionalized homologues (Table 3 ) 
as compared to simple alkyl-chain containing ILs [16,21] could be attributed to the increase in surface activity resulting from introducing an amide functional group in the hydrophobic side chain (Table 2). However, for $\mathrm{C}_{14}$ amide-derivatives the elongation of the chain length did not lead to a significant increase in their biological efficacy. The cut-off effect observed in biological activity could be attributed to the aggregation process of molecules in aqueous solution [56]. Thus, despite the better surface activity of $\mathrm{C}_{14}$ homologues, its tendency to form molecular aggregates at lower concentrations limits the rate of diffusion to the cell surface [56].

\section{Conclusions}

Long-chain imidazolium- and pyridinium-based ILs incorporating an amide functional group in the alkyl side chain behave as conventional cationic surfactants in aqueous solution and possess a superior surface activity as compared to the corresponding simple alkyl substituted ionic liquids. Its tendency to self-assembly increases with the elongation of the alkyl chain length attached to the polar headgroup. The cmc values obtained for amide-functionalized ILs are lower than for non-functionalized salts indicating that the introduction of an amide group in the alkyl side chain facilitates micellization likely by the hydrogen-bonding between amide groups in the head group region. The incorporation of an amide group significantly improves the thermal stability of the ILs by increasing the decomposition temperature about $20-40^{\circ} \mathrm{C}$ as compared to non-functionalized ionic liquids. Imidazolium- and pyridinium-based ILs containing an amide moiety show a broad-spectrum of antimicrobial activity against common bacteria and fungi and their efficiency as antimicrobial agents is related to the length of the alkyl side chain. The compounds with alkyl chains $\leq 8$ carbon atoms are not active against bacteria and fungi whereas 
the ILs containing from 10 to 14 carbon atoms in the alkyl chain show prominent antimicrobial activity, being the $\mathrm{C}_{12}$ homologous the most efficient antimicrobial agents. As compared to nonfunctionalized ILs, ionic liquids containing an amide group show a similar antimicrobial activity against Gram positive and Gram negative microorganisms and a significant increase of antifungal activity.

This work reveals that the incorporation of a hydrogen bonding functionality attached to the polar headgroup increases the thermal stability of the imidazolium and pyridinium salts, facilitates micellization and enhances the antifungal activity. The better understanding of the factors affecting micellization and biological activity of the long-chain ionic liquids reported in this study is expected to contribute to the design and development of new functionalized ionic liquids with improved physicochemical and biological properties for separation processes, biocatalysis and preparation of nanoestructured materials.

\section{Acknowledgments}

We thank the Spanish Ministry of Economia y Competitividad (CTQ2013-41514-P) for financial support.

\section{Appendix A. Supplementary data.}

Synthesis procedures and characterization of N-alkyl-2-bromoacetamides $\left({ }^{1} \mathrm{H}-\mathrm{NMR},{ }^{13} \mathrm{C}\right.$ NMR) and ionic liquids ( ${ }^{1} \mathrm{H}-\mathrm{NMR},{ }^{13} \mathrm{C}-\mathrm{NMR}$, mass spectroscopic analysis ESI-MS data); graphs of specific conductivity versus ionic liquid concentration in water at $25^{\circ} \mathrm{C}$ for $\left[\mathrm{C}_{\mathrm{n}} \mathrm{AMeImBr}\right]$ and $\left[\mathrm{C}_{\mathrm{n}} \mathrm{APyrBr}\right](\mathrm{n}=6,8,10$ and 14$)$. 


\section{References}

[1] N.V. Plechkova, K.R. Seddon, Applications of ionic liquids in the chemical industry, Chem. Soc. Rev. 37 (2008) 123-150. doi:10.1039/b006677j.

[2] F. van Rantwijk, R.A. Sheldon, Biocatalysis in ionic liquids, Chem. Rev. 107 (2007) 27572785. doi:10.1021/cr050946x.

[3] H. Olivier-Bourbigou, L. Magna, D. Morvan, Ionic liquids and catalysis: Recent progress from knowledge to applications, Appl. Catal. -Gen. 373 (2010) 1-56. doi:10.1016/j.apcata.2009.10.008.

[4] C.F. Poole, S.K. Poole, Extraction of organic compounds with room temperature ionic liquids, J. Chromatogr. A. 1217 (2010) 2268-2286. doi:10.1016/j.chroma.2009.09.011.

[5] T. Torimoto, T. Tsuda, K. Okazaki, S. Kuwabata, New Frontiers in Materials Science Opened by Ionic Liquids, Adv. Mater. 22 (2010) 1196-1221. doi:10.1002/adma.200902184.

[6] J. Dupont, J.D. Scholten, On the structural and surface properties of transition-metal nanoparticles in ionic liquids, Chem. Soc. Rev. 39 (2010) 1780-1804. doi:10.1039/b822551f.

[7] M.T. Garcia, N. Gathergood, P. Scammells, Biodegradable ionic liquids - Part II. Effect of the anion and toxicology, Green Chem. 7 (2005) 9-14. doi:10.1039/b411922c.

[8] S. Morrissey, B. Pegot, D. Coleman, M.T. Garcia, D. Ferguson, B. Quilty, N. Gathergood, Biodegradable, non-bactericidal oxygen-functionalised imidazolium esters: A step towards "greener" ionic liquids, Green Chem. 11 (2009) 475-483.

[9] S.G. Lee, Functionalized imidazolium salts for task-specific ionic liquids and their applications, Chem. Commun. (2006) 1049-1063. doi:10.1039/b514140k.

[10] H. Zhao, C.L. Jones, J.V. Cowins, Lipase dissolution and stabilization in etherfunctionalized ionic liquids, Green Chem. 11 (2009) 1128-1138. doi:10.1039/b905388c.

[11] H. Li, Z. Li, J. Yin, C. Li, Y. Chi, Q. Liu, Liquid-liquid extraction process of amino acids by a new amide-based functionalized ionic liquid, Green Chem. 14 (2012) 1721-1727. doi:10.1039/c2gc16560k.

[12] J. Bowers, C.P. Butts, P.J. Martin, M.C. Vergara-Gutierrez, R.K. Heenan, Aggregation behavior of aqueous solutions of ionic liquids, Langmuir. 20 (2004) 2191-2198. doi:10.1021/la035940m.

[13] B. Dong, N. Li, L.Q. Zheng, L. Yu, T. Inoue, Surface adsorption and micelle formation of surface active ionic liquids in aqueous solution, Langmuir. 23 (2007) 4178-4182. doi:10.1021/la0633029.

[14] C. Jungnickel, J. Luczak, J. Ranke, J.F. Fernandez, A. Muller, J. Thoming, Micelle formation of imidazolium ionic liquids in aqueous solution, Colloids Surf. -Physicochem. Eng. Asp. 316 (2008) 278-284. doi:10.1016/j.colsurfa.2007.09.020.

[15] M. Blesic, A. Lopes, E. Melo, Z. Petrovski, N.V. Plechkova, J.N.C. Lopes, On the selfaggregation and fluorescence quenching aptitude of surfactant ionic liquids, J. Phys. Chem. B. 112 (2008) 8645-8650. doi:10.1021/jp802179j.

[16] A. Cornellas, L. Perez, F. Comelles, I. Ribosa, A. Manresa, M. T. Garcia, Self-aggregation and antimicrobial activity of imidazolium- and pyridinium-based ionic liquids in aqueous solution, J. Colloid Interface Sci. 355 (2011) 164-171. doi:10.1016/j.jcis.2010.11.063. 
[17] J. Luczak, J. Hupka, J. Thoming, C. Jungnickel, Self-organization of imidazolium ionic liquids in aqueous solution, Colloids Surf. -Physicochem. Eng. Asp. 329 (2008) 125-133. doi:10.1016/j.colsurfa.2008.07.012.

[18] X.Q. Wang, L. Yu, J.J. Jiao, H.N. Zhang, R. Wang, H. Chen, Aggregation behavior of $\mathrm{COOH}$-functionalized imidazolium-based surface active ionic liquids in aqueous solution, J. Mol. Liq. 173 (2012) 103-107. doi:10.1016/j.molliq.2012.06.023.

[19] V. Chauhan, S. Singh, A. Bhadani, Synthesis, characterization and surface properties of long chain beta-hydroxy-gamma-alkyloxy-N-methylimidazolium surfactants, Colloids Surf. -Physicochem. Eng. Asp. 395 (2012) 1-9. doi:10.1016/j.colsurfa.2011.11.022.

[20] M.T. Garcia, I. Ribosa, L. Perez, A. Manresa, F. Comelles, Aggregation behavior and antimicrobial activity of ester-functionalized imidazolium- and pyridinium-based ionic liquids in aqueous solution, Langmuir. 29 (2013) 2536-2545.

[21] J. Pernak, K. Sobaszkiewicz, I. Mirska, Anti-microbial activities of ionic liquids, Green Chem. 5 (2003) 52-56. doi:10.1039/b207543c.

[22] M.T. Garcia, N. Gathergood, P.J. Scammells, Biodegradable ionic liquids Part II. Effect of the anion and toxicology, Green Chem. 7 (2005) 9-14.

[23] J. Ranke, K. Molter, F. Stock, U. Bottin-Weber, J. Poczobutt, J. Hoffmann, Biological effects of imidazolium ionic liquids with varying chain lengths in acute Vibrio fischeri and WST-1 cell viability assays (vol 58, pg 396, 2004), Ecotoxicol. Environ. Saf. 60 (2005) $350-350$.

[24] S. Morrissey, B. Pegot, D. Coleman, M.T. Garcia, D. Ferguson, B. Quilty, N. Gathergood, Biodegradable, non-bactericidal oxygen-functionalised imidazolium esters: A step towards "greener" ionic liquids, Green Chem. 11 (2009) 475-483. doi:10.1039/b812809j.

[25] N. Gathergood, M.T. Garcia, P. Scammells, Biodegradable ionic liquids: Part I. Concept, preliminary targets and evaluation, Green Chem. 6 (2004) 166-175. doi:10.1039/b315270g.

[26] S. Kanjilal, S. Sunitha, P.S. Reddy, K.P. Kumar, U.S.N. Murty, R.B.N. Prasad, Synthesis and evaluation of micellar properties and antimicrobial activities of imidazole-based surfactants, Eur. J. Lipid Sci. Technol. 111 (2009) 941-948. doi:10.1002/ejlt.200800292.

[27] B. Dong, X.Y. Zhao, L.Q. Zheng, J. Zhang, N. Li, T. Inoue, Aggregation behavior of longchain imidazolium ionic liquids in aqueous solution: Micellization and characterization of micelle microenvironment, Colloids Surf. -Physicochem. Eng. Asp. 317 (2008) 666-672. doi:10.1016/j.colsurfa.2007.12.001.

[28] K. Kalyanasundaram, J.K. Thomas, Environmental effects on vibronic band intensities in pyrene monomer fluorescence and their application in studies of micellar systems, J. Am. Chem. Soc. 99 (1977) 2039-2044.

[29] R.N. Jones, A.L. Barry, T.L. Gavan, Manual of Clinical Microbiology, 4th ed., American Society for Microbiology, Washington DC, 1985.

[30] C.P. Fredlake, J.M. Crosthwaite, D.G. Hert, S. Aki, J.F. Brennecke, Thermophysical properties of imidazolium-based ionic liquids, J. Chem. Eng. Data. 49 (2004) 954-964. doi:10.1021/je034261a.

[31] I.H.J. Arellano, J.G. Guarino, F.U. Paredes, S.D. Arco, Thermal stability and moisture uptake of 1-alkyl-3-methylimidazolium bromide, J. Therm. Anal. Calorim. 103 (2011). doi:10.1007/s10973-010-0992-5.

[32] J.G. Huddleston, A.E. Visser, W.M. Reichert, H.D. Willauer, G.A. Broker, R.D. Rogers, Characterization and comparison of hydrophilic and hydrophobic room temperature ionic liquids incorporating the imidazolium cation, Green Chem. 3 (2001) 156-164. 
[33] R. Aggarwal, S. Singh, G. Hundal, Synthesis, Characterization, and Evaluation of Surface Properties of Cyclohexanoxycarbonylmethylpyridinium and Cyclohexanoxycarbonylmethylimidazolium Ionic Liquids, Ind. Eng. Chem. Res. 52 (2013) 1179-1189. doi:10.1021/ie3020473.

[34] R. Vanyur, L. Biczok, Z. Miskolczy, Micelle formation of 1-alkyl-3-methylimidazolium bromide ionic liquids in aqueous solution, Colloids Surf. -Physicochem. Eng. Asp. 299 (2007) 256-261. doi:10.1016/j.colsurfa.2006.11.049.

[35] H. Hoffmann, W. Ulbricht, Kinetic and thermodynamic measurements on aggregation of perfluorinated surfactants, Z. Phys. Chem.-Frankf. 106 (1977) 167-184.

[36] M. Blesic, M.H. Marques, N.V. Plechkova, K.R. Seddon, L.P.N. Rebelo, A. Lopes, Selfaggregation of ionic liquids: micelle formation in aqueous solution, Green Chem. 9 (2007) 481-490. doi:10.1039/b615406a.

[37] N.V. Sastry, N.M. Vaghela, P.M. Macwan, S.S. Soni, V.K. Aswal, A. Gibaud, Aggregation behavior of pyridinium-based ionic liquids in water - Surface tension, H-1 NMR chemical shifts, SANS and SAXS measurements, J. Colloid Interface Sci. 371 (2012) 52-61. doi:10.1016/j.jcis.2011.12.077.

[38] M.T. Garcia, E. Campos, M. Dalmau, I. Ribosa, J. Sanchez-Leal, Structure-activity relationships for association of linear alkylbenzene sulfonates with activated sludge, Chemosphere. 49 (2002) 279-286. doi:10.1016/S0045-6535(02)00182-0.

[39] M.J. Rosen, Surfactants and Interfacial Phenomana, 3rd ed., Wiley Interscience, New York, 2004.

[40] S. Shimizu, O.A. El Seoud, Synthesis and aggregation of benzyl(2acylaminoethyl)dimethylammonium chloride surfactants, Langmuir. 19 (2003) 238-243. doi: $10.1021 / 1 \mathrm{la} 026286 \mathrm{y}$.

[41] H.B. Klevens, Structure and aggregation in dilute solutions of surface active agents, J. Am. Oil Chem. Soc. 30 (1953) 74-80. doi:10.1007/bf02635002.

[42] Q.Q. Baltazar, J. Chandawalla, K. Sawyer, J.L. Anderson, Interfacial and micellar properties of imidazolium-based monocationic and dicationic ionic liquids, Colloids Surf. Physicochem. Eng. Asp. 302 (2007) 150-156. doi:10.1016/j.colsurfa.2007.02.012.

[43] O.A. El Seoud, P.A.R. Pires, T. Abdel-Moghny, E.L. Bastos, Synthesis and micellar properties of surface-active ionic liquids: 1-Alkyl-3-methylimidazolium chlorides, J. Colloid Interface Sci. 313 (2007) 296-304. doi:10.1016/j.jcis.2007.04.028.

[44] L.J. Shi, N. Li, H. Yan, Y.A. Gao, L.Q. Zheng, Aggregation Behavior of Long-Chain NAryl Imidazolium Bromide in Aqueous Solution, Langmuir. 27 (2011) 1618-1625. doi: $10.1021 / 1 \mathrm{a} 104719 \mathrm{v}$.

[45] P.C. HiemenZ, R. Rajagopalan, Principles of Colloid and Surface Chemistry, Marcel Dekker Inc., New York, 1997.

[46] I. Goodchild, L. Collier, S.L. Millar, I. Prokes, J.C.D. Lord, C.P. Butts, Structural studies of the phase, aggregation and surface behaviour of 1-alkyl-3-methylimidazolium halide plus water mixtures, J. Colloid Interface Sci. 307 (2007) 455-468. doi:10.1016/j.jcis.2006.11.034.

[47] A. Modaressi, H. Sifaoui, M. Mielcarz, U. Domanska, M. Rogalski, Influence of the molecular structure on the aggregation of imidazolium ionic liquids in aqueous solutions, Colloids Surf. -Physicochem. Eng. Asp. 302 (2007) 181-185. doi:10.1016/j.colsurfa.2007.02.020. 
[48] N.V. Sastry, N.M. Vaghela, V.K. Aswal, Effect of alkyl chain length and head group on surface active and aggregation behavior of ionic liquids in water, Fluid Phase Equilibria. 327 (2012) 22-29. doi:10.1016/j.fluid.2012.04.013.

[49] F. Kopecky, Micellization and other associations of amphiphilic antimicrobial quaternary ammonium salts in aqueous solutions, Pharmazie. 51 (1996) 135-144.

[50] L. Perez, A. Pinazo, M.T. Garcia, M. Lozano, A. Manresa, M. Angelet, M.R. Infante, Cationic surfactants from lysine: Synthesis, micellization and biological evaluation, Eur. J. Med. Chem. 44 (2009) 1884-1892. doi:10.1016/j.ejmech.2008.11.003.

[51] L. Perez, A. Pinazo, M.T. Garcia, M.C. Moran, M.R. Infante, Monoglyceride surfactants from arginine: synthesis and biological properties, New J. Chem. 28 (2004) 1326-1334. doi: $10.1039 / \mathrm{b} 405733 \mathrm{c}$.

[52] L. Carson, P.K.W. Chau, M.J. Earle, M.A. Gilea, B.F. Gilmore, S.P. Gorman, Antibiofilm activities of 1-alkyl-3-methylimidazolium chloride ionic liquids, Green Chem. 11 (2009) 492-497. doi:10.1039/b821842k.

[53] T.J. Franklin, G.A. Snow, Biochemistry of Antimicrobial Action, 4th ed., London, 1989.

[54] D. Demberelnyamba, K.S. Kim, S.J. Choi, S.Y. Park, H. Lee, C.J. Kim, Synthesis and antimicrobial properties of imidazolium and pyrrolidinonium salts, Bioorg. Med. Chem. 12 (2004) 853-857. doi:10.1016/j.bmc.2004.01.003.

[55] S.N. Riduan, Y. Zhang, Imidazolium salts and their polymeric materials for biological applications, Chem. Soc. Rev. 42 (2013) 9055-9070. doi:10.1039/c3cs60169b.

[56] J. Luczak, C. Jungnickel, I. Lacka, S. Stolle, J. Hupka, Antimicrobial and surface activity of 1-alkyl-3-methylimidazolium derivatives, Green Chem. 12 (2010) 593-601. doi:10.1039/b921805j. 